\title{
Design of V-Substituted TiFe-Based Alloy for Target Pressure Range and Easy Activation
}

\author{
Mohammad Faisal ${ }^{1, *,+}$, June-Hyung Kim ${ }^{1,2,+} \mathbb{C}$, Young Whan Cho ${ }^{1}$, Jae-il Jang ${ }^{2}$, Jin-Yoo Suh ${ }^{1} \mathbb{D}$, \\ Jae-Hyeok Shim ${ }^{1}$ and Young-Su Lee ${ }^{1, *(D)}$ \\ 1 Center for Energy Materials Research, Korea Institute of Science and Technology, Seoul 02792, Korea; \\ 120019@kist.re.kr (J.-H.K.); oze@kist.re.kr (Y.W.C.); jinyoo@kist.re.kr (J.-Y.S.); jhshim@kist.re.kr (J.-H.S.) \\ 2 Division of Materials Science and Engineering, Hanyang University, Seoul 04763, Korea; jijang@hanyang.ac.kr \\ * Correspondence: faisal.mse@hotmail.com (M.F.); lee0su@kist.re.kr (Y.-S.L.) \\ $\dagger$ These authors contributed equally to this paper.
}

Citation: Faisal, M.; Kim, J.-H.; Cho, Y.W.; Jang, J.; Suh, J.-Y.; Shim, J.-H.; Lee, Y.-S. Design of V-Substituted TiFe-Based Alloy for Target Pressure Range and Easy Activation. Materials 2021, 14, 4829. https://doi.org/10.3390/ma14174829

Academic Editor:

Haralampos N. Miras

Received: 4 August 2021

Accepted: 23 August 2021

Published: 25 August 2021

Publisher's Note: MDPI stays neutral with regard to jurisdictional claims in published maps and institutional affiliations.

Copyright: (c) 2021 by the authors. Licensee MDPI, Basel, Switzerland. This article is an open access article distributed under the terms and conditions of the Creative Commons Attribution (CC BY) license (https:// creativecommons.org/licenses/by/ $4.0 /)$.

\begin{abstract}
Titanium iron (TiFe) alloy is a room-temperature hydrogen-storage material, and it absorbs hydrogen via a two-step process to form $\mathrm{TiFeH}$ and then $\mathrm{TiFeH}_{2}$. The effect of $\mathrm{V}$ addition in TiFe alloy was recently elucidated. The $\mathrm{V}$ substitution for Ti sublattice lowers $P_{2} / P_{1}$ ratio, where $P_{1}$ and $P_{2}$ are the equilibrium plateau pressure for $\mathrm{TiFe} / \mathrm{TiFeH}$ and $\mathrm{TiFeH} / \mathrm{TiFeH}_{2}$, respectively, and thus restricts the two-step hydrogenation within a narrow pressure range. The focus of the present investigation was to optimize the $\mathrm{V}$ content such that maximum usable storage capacity can be achieved for the target pressure range: $1 \mathrm{MPa}$ for absorption and $0.1 \mathrm{MPa}$ for desorption. The effect of $\mathrm{V}$ substitution at selective $\mathrm{Ti}$ or Fe sublattices was closely analyzed, and the alloy composition $\mathrm{Ti}_{46} \mathrm{Fe}_{47.5} \mathrm{~V}_{6.5}$ displayed the best performance with ca. $1.5 \mathrm{wt}$.\% of usable capacity within the target pressure range. At the same time, another issue in TiFe-based alloys, which is a difficulty in activation at room temperature, was solved by Ce addition. It was shown that $3 \mathrm{wt} . \%$ Ce dispersion in TiFe alloy imparted to it easy room-temperature (RT) activation properties.
\end{abstract}

Keywords: hydrogen storage; TiFe alloy; equilibrium pressure; activation

\section{Introduction}

The increasing demand for an alternative to fossil fuel has stimulated hydrogenstorage research. The room-temperature hydrogen-storage alloy TiFe is the forerunner in the quest for a suitable medium owing to the abundance of constituting elements and appreciable hydrogen-storage capacity of $1.9 \mathrm{wt} . \% \mathrm{H}$ [1,2] near ambient temperature and pressure. The two major bottlenecks must be overcome to commercialize TiFe alloy as a room-temperature hydrogen-storage material. First, the initial hydrogenation, or activation, should be carried out at room temperature. A high-temperature activation procedure was usually involved for activating pure TiFe [1]. Second, usable capacity under a practical operation pressure range, e.g., $1 \mathrm{MPa}$ for hydrogen absorption and $0.1 \mathrm{MPa}$ for desorption, must be increased. Hydrogenation of TiFe proceeds in two steps, sequentially forming TiFeH monohydride and $\mathrm{TiFeH}_{2}$ dihydride. The ratio of equilibrium pressure for each step, $P_{2} / P_{1}\left(P_{1}\right.$ and $P_{2}$ are the equilibrium plateau pressure for TiFe/TiFeH and $\mathrm{TiFeH} / \mathrm{TiFeH}_{2}$, respectively), should be minimized to ensure large usable capacity in a narrow pressure range [2].

Available studies emphasized the characterization of the TiFe alloy, and only a few attempted to optimize the operation pressure range. Ternary phase diagram observations revealed that most of the elemental substitutions (e.g., $\mathrm{Mn}, \mathrm{Co}, \mathrm{Cr}, \mathrm{Ni}$, and $\mathrm{Zr}$ ) resulted in the formation of secondary phases [3-10] dispersed uniformly in the TiFe-based primary phase [11], which was unavoidable because of the narrow single-phase region of the TiFe phase. The resultant improvement in the initial activation and other hydrogen-storage 
properties of TiFe alloys was attributed to the presence of these secondary hydrogenabsorbing phases $[12,13]$. For instance, easy activation of $\mathrm{Zr}$-added TiFe alloy reported in some studies [13-16] is likely due to the formation of Ti-Fe-Zr-based ternary alloy: Faisal et al. [17] recently reported that single-phase Ti-Fe-Zr ternary alloys in the C14 structure were easily activated under $3 \mathrm{MPa}$ of hydrogen pressure at room temperature. Likewise, Cr-added TiFe alloy could be activated at room temperature with the help of a $\mathrm{Ti}(\mathrm{Fe}, \mathrm{Cr})_{2}$ phase in the $\mathrm{C} 14$ structure [18-20]. However, in those studies, the two-step plateaus became more pronounced after alloying, i.e., $P_{2} / P_{1}$ became larger. Hence, it is necessary to use alloying elements that can improve activation without modifying the thermodynamics of the TiFe phase. It was reported that over-stoichiometric Ti or the addition of mischmetal $(\mathrm{Mm})$ in small quantity improved the activation properties of TiFe alloy drastically [21-23]. Ma et al. [24] showed that $\mathrm{FeTi}_{1.3}+\mathrm{x}$ wt. $\% \mathrm{Mm}(\mathrm{x}=1.5,3.0$, $4.5,6.0$ ) were hydrogenated at room temperature, with $\mathrm{FeTi}_{1.3}+6 \mathrm{wt} . \% \mathrm{Mm}$ showing $1.58 \mathrm{wt} . \% \mathrm{H}$-storage capacity. Wang et al. [22] studied hydrogen-storage properties of $\mathrm{Ti}_{\mathrm{x}} \mathrm{Fe}+\mathrm{y} \mathrm{wt} . \% \mathrm{La}$. La in small quantities helped improve activation of TiFe alloy without degrading hydrogen-storage capacity substantially. It has been established in previous studies [25] that the addition of a small amount of Ce showed remarkable improvement in the activation properties of $\mathrm{TiFe}_{0.9} \mathrm{Mn}_{0.1}$ at $353 \mathrm{~K}$ and $4 \mathrm{MPa}$ hydrogen pressure, which was otherwise virtually impossible to activate under the above conditions [26]. Liu et al. [27] and Yan et al. [28] showed Ce segregation in Ce-containing BCC alloy. They showed that this segregation had no effect on the alloy structure and its lattice parameter. It was mentioned that $\mathrm{Ce}$-containing alloys showed $\mathrm{Ce}$ and $\mathrm{CeO}_{2}$ enrichment, and $\mathrm{Ce}$ reacted with hydrogen, imparting RT activation properties to the alloys. Therefore, adding some percentage of Lanthanide elements can be a good strategy to solve the activation issue.

To tailor the operation pressure range of hydrogen storage via alloying, the alloy composition should stay within the single-phase TiFe in the B2 structure. It is worth mentioning that most of the element alloying with TiFe replaces Fe sublattice [15,29-32]. The conventional knowledge about Fe substitution with most-studied elements such as $\mathrm{Ni}, \mathrm{Co}$, and $\mathrm{Cr}$ is that they result in a significant reduction in $P_{1}$, which in turn increases $P_{2} / P_{1}$ ratio. The element $\mathrm{Mn}$, in contrast, leads to a lesser reduction in equilibrium pressure $[26,33,34]$. Liu et al. [35] showed that TiFe-based alloy demonstrated as $\mathrm{Fe}_{1-\mathrm{x}} \mathrm{Mn}_{\mathrm{x}} \mathrm{Ti}_{1-\mathrm{y}} \mathrm{V}_{\mathrm{y}}$ had the ability to absorb and desorb hydrogen under close-to-constant pressure, implying $P_{2} / P_{1}$ ratio approaching unity. This resulted in the enhancement of usable maximum hydrogen capacity in a narrow pressure range. Mitrokhin et al. [36] highlighted that the desorption pressure-composition isotherm curves for Ti-Fe-V-Mn alloys had the plateaus both approaching each other and being combined into one single sloping plateau. They coined the term "pressure smoothing effect" to explain the phenomenon. Massicot [37] illustrated that $\mathrm{Ti}_{47} \mathrm{~V}_{5} \mathrm{Fe}_{48}$ displayed a sloping plateau over the complete absorption/desorption domain without a detectable two-step plateau. Jung et al. [2] pointed out the importance of $\mathrm{V}$, which can substitute for both Ti and Fe sites [38] unlike the other $3 d$ transition metals. This allowed more degrees of freedom in tailoring the two equilibrium pressures, $P_{1}$ and $P_{2}$, and an optimal hydrogen-storage property can be derived only through $V$ without resorting to additional alloying elements.

In the current discussion, we present a systematic study of designing an optimal composition of V-substituted TiFe alloy, exhibiting $P_{2} / P_{1}$ ratio close to unity, thus maximizing the usable capacity under the target pressure range of $0.1-1 \mathrm{MPa}$. We utilized the unique property of V, i.e., its versatility to substitute for $\mathrm{Fe}$ and $\mathrm{Ti}$, simultaneously. The role of $\mathrm{Ce}$ addition in improving the RT activation of V-substituted TiFe alloy was also envisaged. Thus, we propose a novel V-substituted TiFe alloy with Ce addition as a prime material sorted for RT solid-state hydrogen-storage applications. 


\section{Materials and Methods}

\subsection{Sample Synthesis}

A binary Ti-Fe alloy and eight ternary Ti-Fe-V alloys with $3 \mathrm{wt} . \%$ Ce addition (samples 0 to 8 ) were synthesized via arc melting under argon ( $6 \mathrm{~N}$ purity) atmosphere. The elements $\mathrm{Ti}, \mathrm{Fe}$, and $\mathrm{V}$ were $99.995 \%, 99.9 \%$, and $99.95 \%$ pure, respectively. The required proportions of the elements were weighed such that each alloy was $25 \mathrm{~g}( \pm 0.005 \mathrm{~g})$. All the alloys were melted six times by flipping the sample button between two consecutive melting procedures to enhance the compositional homogeneity. The weight loss of the alloys after the arc melting was $<0.5 \%$. The alloys were wrapped in tantalum foil and vacuum-sealed in quartz tubes. The first six alloys (0-5) were annealed at $1000{ }^{\circ} \mathrm{C}$ for a week while the last three (6-8) were annealed for three weeks at $1000{ }^{\circ} \mathrm{C}$. Table 1 presents nominal compositions for each alloy along with respective sample IDs. Alloy 0 is the reference alloy without $\mathrm{V}$ substitution. Assuming that $\mathrm{Ti}$ and $\mathrm{Fe}$ are preferentially positioned at their own sublattices, $\mathrm{V}$ distribution at the Ti and Fe sublattices was determined and is summarized in Table 1.

Table 1. Nominal composition of the samples from 0 to 8 . The subscripts indicate at $\%$ of the corresponding elements. Third and fourth columns show atom distribution at the Ti and Fe sublattices.

\begin{tabular}{cccc}
\hline Sample ID & Nominal Composition & Ti Sublattice & $\mathrm{Fe} \mathrm{Sublattice}$ \\
\hline 0 & $\mathrm{Ti}_{51} \mathrm{Fe}_{49}$ & $\mathrm{Ti}_{50}$ & $\mathrm{Fe}_{49} \mathrm{Ti}_{1}$ \\
1 & $\mathrm{Ti}_{51} \mathrm{Fe}_{49} \mathrm{~V}_{1}$ & $\mathrm{Ti}_{50}$ & $\mathrm{Fe}_{4} \mathrm{~V}_{1}$ \\
2 & $\mathrm{Ti}_{51} \mathrm{Fe}_{48} \mathrm{~V}_{1}$ & $\mathrm{Ti}_{50}$ & $\mathrm{Fe}_{48} \mathrm{Ti}_{1} \mathrm{~V}_{1}$ \\
3 & $\mathrm{Ti}_{49} \mathrm{Fe}_{49} \mathrm{~V}_{2}$ & $\mathrm{Ti}_{49} \mathrm{~V}_{1}$ & $\mathrm{Fe}_{49} \mathrm{~V}_{1}$ \\
4 & $\mathrm{Ti}_{50} \mathrm{Fe}_{48} \mathrm{~V}_{2}$ & $\mathrm{Ti}_{50}$ & $\mathrm{Fe}_{48} \mathrm{~V}_{2}$ \\
5 & $\mathrm{Ti}_{51} \mathrm{Fe}_{47} \mathrm{~V}_{2}$ & $\mathrm{Ti}_{50}$ & $\mathrm{Fe}_{47} \mathrm{~T}_{1} \mathrm{~V}_{2}$ \\
6 & $\mathrm{Ti}_{46.5} \mathrm{Fe}_{48} \mathrm{~V}_{5.5}$ & $\mathrm{Ti}_{46.5} \mathrm{~V}_{3.5}$ & $\mathrm{Fe}_{48} \mathrm{~V}_{2}$ \\
7 & $\mathrm{Ti}_{46.5} \mathrm{Fe}_{47.5} \mathrm{~V}_{6}$ & $\mathrm{Ti}_{46.5} \mathrm{~V}_{3.5}$ & $\mathrm{Fe}_{47.5} \mathrm{~V}_{2.5}$ \\
8 & $\mathrm{Ti}_{46} \mathrm{Fe}_{47.5} \mathrm{~V}_{6.5}$ & $\mathrm{Ti}_{46} \mathrm{~V}_{4}$ & $\mathrm{Fe}_{47.5} \mathrm{~V}_{2.5}$ \\
\hline
\end{tabular}

\subsection{Structure and Chemical Composition Analysis}

The crystal structure, phase fractions and lattice parameters of the alloy samples were analyzed via $\mathrm{X}$-ray powder diffraction (XRD) using $\mathrm{Cu}-\mathrm{K} \alpha$ radiation (D8 ADVANCE, Bruker AXS GmbH, Karlsruhe, Germany). Rietveld refinement analysis was performed on the diffraction patterns using TOPAS software (version 5, Bruker AXS GmbH, Karlsruhe, Germany) [39]. The phase fractions and lattice parameters were assessed via whole-profile fitting (WPF). The atomic composition of each phase was analyzed from energy-dispersive x-ray spectroscopy (EDX) on backscattered electron (BSE) images obtained from fieldemission scanning electron microscope (FE-SEM, Inspect F50, FEI Company, Hillsboro, OR, USA). The phase fraction in area percentage was obtained from image analysis using Image J, FIJI, software (version 2, NIH, Bethesda, MD, USA).

\subsection{Hydrogen Sorption Property}

The alloy samples were activated in a lab-made stainless-steel reactor $\left(3 \mathrm{~cm}^{3}\right.$ capacity). The bulk alloy pieces were charged in the reactor, and the reactor was evacuated to $10^{-1} \mathrm{~Pa}$ at $30{ }^{\circ} \mathrm{C}$; $3 \mathrm{MPa}$ of pure hydrogen gas ( $6 \mathrm{~N}$ purity) was introduced inside the reactor at room temperature, and the pressure change was monitored over time. The sample was deemed to be activated when the pressure drop inside the reactor ceased. Pressurecomposition isotherm ( $\mathrm{PCI}$ ) measurement was performed on each sample to evaluate their hydrogen sorption property. Before a PCI measurement, the activated alloy sample inside the reactor was evacuated under dynamic vacuum at $200{ }^{\circ} \mathrm{C}$ for $1 \mathrm{~h}$ to remove any residual hydrogen from the activation process. The PCI curves were obtained at $30^{\circ} \mathrm{C}$ with maximum hydrogen pressure of $4 \mathrm{MPa}$ via an automatic high-pressure volumetric analyzer (HPVA II, Particulate Systems). For sample 8, PCI measurements were made at three different temperatures $\left(30,40\right.$, and $\left.50^{\circ} \mathrm{C}\right)$. 


\section{Results and Discussion}

\subsection{Alloy Design and Phase Study}

Figure 1 shows a portion of the horizontal section of a ternary phase diagram of the Ti-Fe-V system at $1000{ }^{\circ} \mathrm{C}$ (redrawn from [38]), overlaid with the nominal compositions of samples $0-8$, designed for the current study. The nominal compositions from samples $0-5$ were designed in a fashion that the effect of $\mathrm{V}$ substitution at Fe and Ti sublattices becomes evident. The composition of $\mathrm{Ti}_{51} \mathrm{Fe}_{49}$ (the subscript denotes the composition in at $\%$ ) was chosen as the starting composition instead of $\mathrm{Ti}_{50} \mathrm{Fe}_{50}$ because $P_{2}$ of $\mathrm{Ti}_{50} \mathrm{Fe}_{50}$ is higher than $1 \mathrm{MPa}$ at $30^{\circ} \mathrm{C}$ [1], outside the target pressure range in this study. The hydrides of $\mathrm{Ti}_{51} \mathrm{Fe}_{49}$ are more stable than that of $\mathrm{Ti}_{50} \mathrm{Fe}_{50}$. The compositions of samples 6 to 8 were designed such that the usable capacity between 0.1 and $1 \mathrm{MPa}$ should be maximized: this is elaborated later.

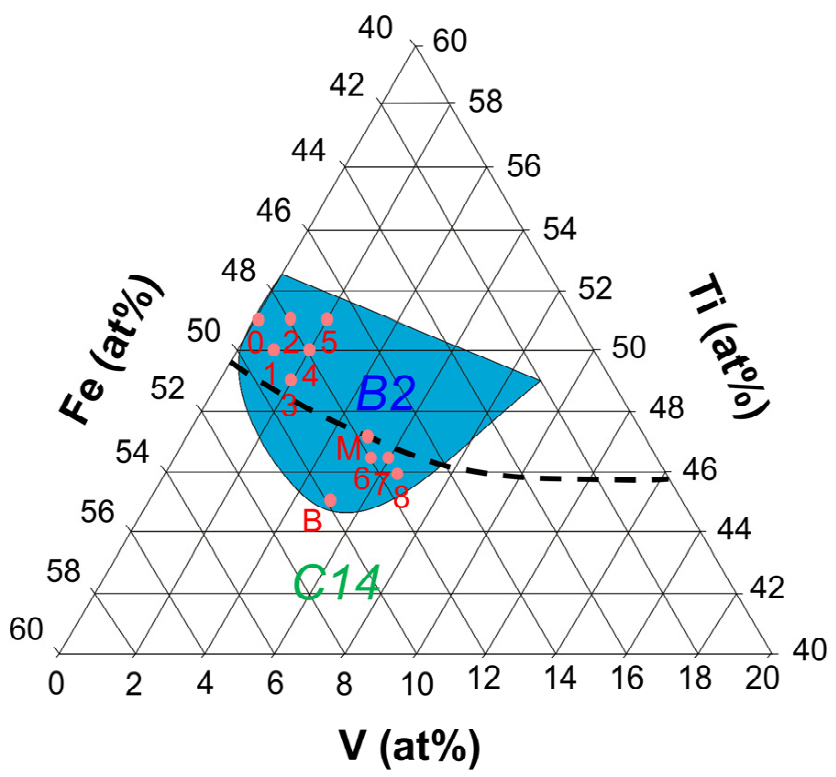

Figure 1. Horizontal section of a ternary phase diagram of Ti-Fe-V system at $1000{ }^{\circ} \mathrm{C}$ [38] overlaid with designed nominal compositions of samples $0-8$ and the two compositions $\mathrm{B}$ and $\mathrm{M}$ from previous studies [2,38]. The shaded region corresponds to a single phase in the B2 structure. The black dashed line is a tentative liquidus surface projection and is a border between the B2 and C14 regions.

The WPF plots from the XRD data of samples 0-8 are shown in Figure 2. Only three phases were detected: TiFe main phase (space group $\mathrm{Pm}-3 \mathrm{~m}$ ) and small amounts of $\mathrm{Ce}$ (space group $F m-3 m$ ) and $\mathrm{CeO}_{2}$ (space group $\mathrm{Fm}-3 m$ ) phases. Precisely speaking, the TiFe main phase is the Ti-Fe-V ternary phase in the B2 structure (in Figure 1), but we henceforth refer to it as a TiFe phase for simplicity. The Rietveld refinement results of the XRD data are summarized in Table 2. The sum of the phase fraction of $\mathrm{Ce}$ and $\mathrm{CeO}_{2}$ was about $3 \mathrm{wt} . \%$, approximately the same as the initial amount of $3 \mathrm{wt} . \% \mathrm{Ce}$. Evidently, Ce is not soluble in TiFe [25] and exists as separate phases. The presence of $\mathrm{CeO}_{2}$ reflects that $\mathrm{Ce}$ acts as an oxygen scavenger, besides promoting initial hydrogenation. At $1000^{\circ} \mathrm{C}$, the standard Gibbs free energy of formation of $\mathrm{CeO}_{2}$ and $\mathrm{TiO}_{2}$ is $-826 \mathrm{~kJ} \mathrm{~mol}^{-1}$ and $-714 \mathrm{~kJ} \mathrm{~mol}^{-1}$, respectively (from HSC Chemistry software, version 5.1, Outokumpu Research Oy, Pori, Finland). This characteristic allows us to precisely control Ti and Fe content in the B2 structure. In a previous study, the $\mathrm{Ti}_{4} \mathrm{Fe}_{2} \mathrm{O}_{1-\mathrm{x}}$ suboxide phase was found, and because of the formation of this suboxide phase, the contents of Ti and Fe were different from those of the nominal composition [2]. In the XRD data, we did not find the peaks related to this suboxide phase. 
(a)
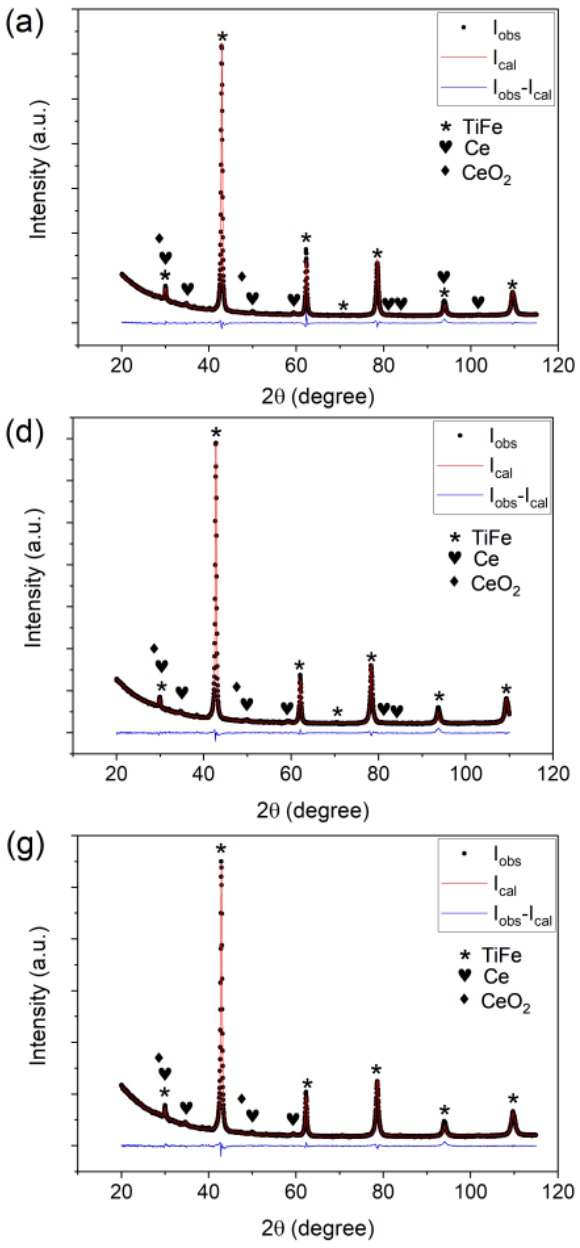

(b)

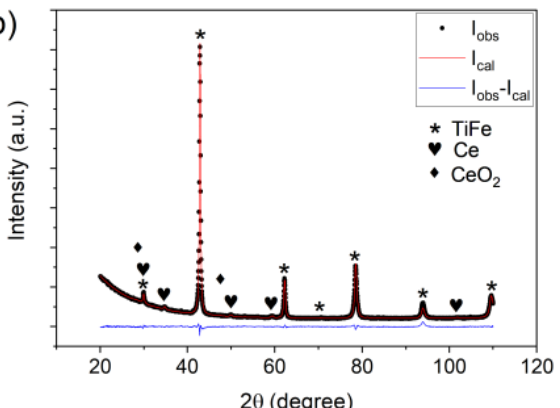

(e)

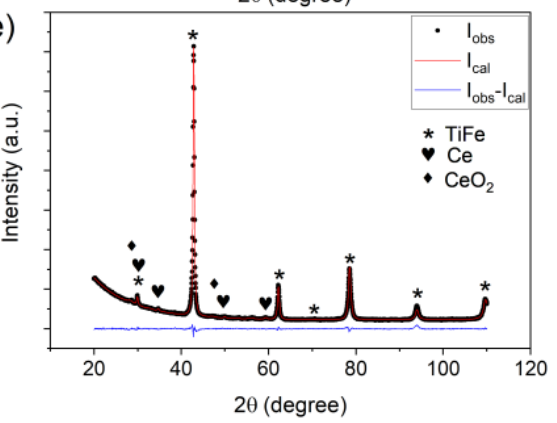

(h)

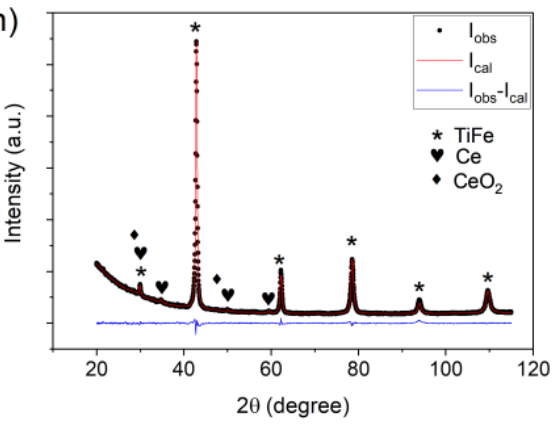

(c)

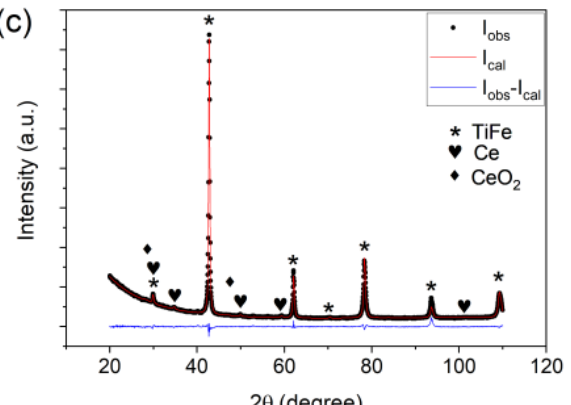

(f)
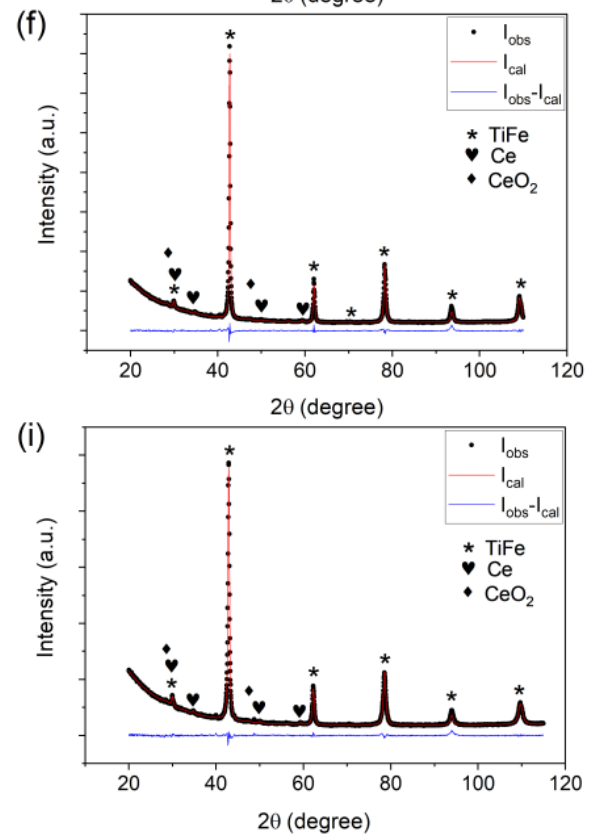

Figure 2. WPF plot for the XRD data from samples: (a) 0 ; (b) 1 ; (c) 2 ; (d) 3 ; (e) 4 ; (f) 5 ; (g) 6 ; (h) 7 ; (i) 8 . The peaks of TiFe, Ce, and $\mathrm{CeO}_{2}$ were indexed. Observed intensity $\left(\mathrm{I}_{\mathrm{obs}}\right)$, calculated intensity $\left(\mathrm{I}_{\mathrm{cal}}\right)$, and the difference $\left(\mathrm{I}_{\mathrm{obs}}-\mathrm{I}_{\text {cal }}\right)$ were plotted in black circles, red line, and blue line, respectively.

Table 2. XRD analysis of the samples. The lattice parameter of the TiFe main phase and the phase fractions determined by the Rietveld refinement of the XRD data in Figure 2. The weighted profile $R$-factor $\left(R_{\mathrm{wp}}\right)$ and the goodness of fit $\left(\chi^{2}\right)$ are listed to show the quality of the fit.

\begin{tabular}{|c|c|c|c|c|c|c|c|}
\hline \multirow{2}{*}{ Sample ID } & \multirow{2}{*}{$\begin{array}{c}\text { Nominal } \\
\text { Composition }\end{array}$} & \multirow{2}{*}{$\begin{array}{c}\text { Lattice } \\
\text { Parameter (Å) }\end{array}$} & \multicolumn{3}{|c|}{ Phase Fraction (wt.\%) } & \multirow{2}{*}{$R_{\mathrm{wp}}(\%)$} & \multirow{2}{*}{$x^{2}$} \\
\hline & & & TiFe & $\mathrm{Ce}$ & $\mathrm{CeO}_{2}$ & & \\
\hline 0 & $\mathrm{Ti}_{51} \mathrm{Fe}_{49}$ & $2.98327(5)$ & $96.9(2)$ & $1.3(1)$ & $1.8(2)$ & 3.52 & 2.83 \\
\hline 1 & $\mathrm{Ti}_{50} \mathrm{Fe}_{49} \mathrm{~V}_{1}$ & $2.98241(7)$ & $97.2(2)$ & $1.4(1)$ & $1.4(2)$ & 3.41 & 2.15 \\
\hline 2 & $\mathrm{Ti}_{51} \mathrm{Fe}_{48} \mathrm{~V}_{1}$ & $2.98764(6)$ & $97.2(3)$ & $1.1(1)$ & $1.7(3)$ & 4.07 & 2.57 \\
\hline 3 & $\mathrm{Ti}_{49} \mathrm{Fe}_{49} \mathrm{~V}_{2}$ & $2.98058(7)$ & $97.5(2)$ & $0.9(1)$ & $1.6(1)$ & 3.09 & 2.00 \\
\hline 4 & $\mathrm{Ti}_{50} \mathrm{Fe}_{48} \mathrm{~V}_{2}$ & $2.98690(6)$ & $96.8(3)$ & $1.3(1)$ & $1.9(3)$ & 3.28 & 2.10 \\
\hline 5 & $\mathrm{Ti}_{51} \mathrm{Fe}_{47} \mathrm{~V}_{2}$ & $2.99072(6)$ & $97.5(2)$ & $1.0(1)$ & $1.5(1)$ & 3.54 & 2.21 \\
\hline 6 & $\mathrm{Ti}_{46.5} \mathrm{Fe}_{48} \mathrm{~V}_{5.5}$ & $2.98008(6)$ & $96.7(2)$ & $1.2(1)$ & $2.1(2)$ & 3.29 & 1.93 \\
\hline 7 & $\mathrm{Ti}_{46.5} \mathrm{Fe}_{47.5} \mathrm{~V}_{6}$ & $2.98179(6)$ & $96.9(2)$ & $1.0(1)$ & $2.1(2)$ & 3.04 & 1.79 \\
\hline 8 & $\mathrm{Ti}_{46} \mathrm{Fe}_{47.5} \mathrm{~V}_{6.5}$ & $2.98122(7)$ & $96.5(2)$ & $1.1(1)$ & $2.4(2)$ & 3.26 & 1.89 \\
\hline
\end{tabular}

In samples 0-5, although the composition change stayed within 2 at.\%, the lattice parameters in Table 2 were systematically varied according to the composition. From now on, the change in alloy composition from one sample to another is represented by ' $\rightarrow$ '. For instance, if the composition of sample 0 changes to 1 , it would be represented as $0 \rightarrow 1$. Table 2 shows that samples $0 \rightarrow 1 \rightarrow 3$ have Fe composition fixed to 49 at.\%, with increasing $\mathrm{V}$ in $0 \rightarrow 1 \rightarrow 2$ at.\% and decreasing Ti in $51 \rightarrow 50 \rightarrow 49$ at.\%. The atomic radii for the elements 
are in the following order: $\mathrm{Ti}>\mathrm{V}>\mathrm{Fe}$. Therefore, when $\mathrm{V}$ substitutes for $\mathrm{Ti}(\mathrm{V} \rightarrow \mathrm{Ti})$, the lattice parameter must decrease. This trend is illustrated in Figure 3. Similarly, samples $0 \rightarrow 2 \rightarrow 5$ have Ti composition fixed at 51 at $\%$ with $\mathrm{V}$ substituting for $\mathrm{Fe}(\mathrm{V} \rightarrow \mathrm{Fe})$. The lattice parameter monotonically increased in this series. For samples $3 \rightarrow 4 \rightarrow 5$, Ti substituted for $\mathrm{Fe}(\mathrm{Ti} \rightarrow \mathrm{Fe})$, and again the lattice parameter increased showing the largest slope among the three series in Figure 3.

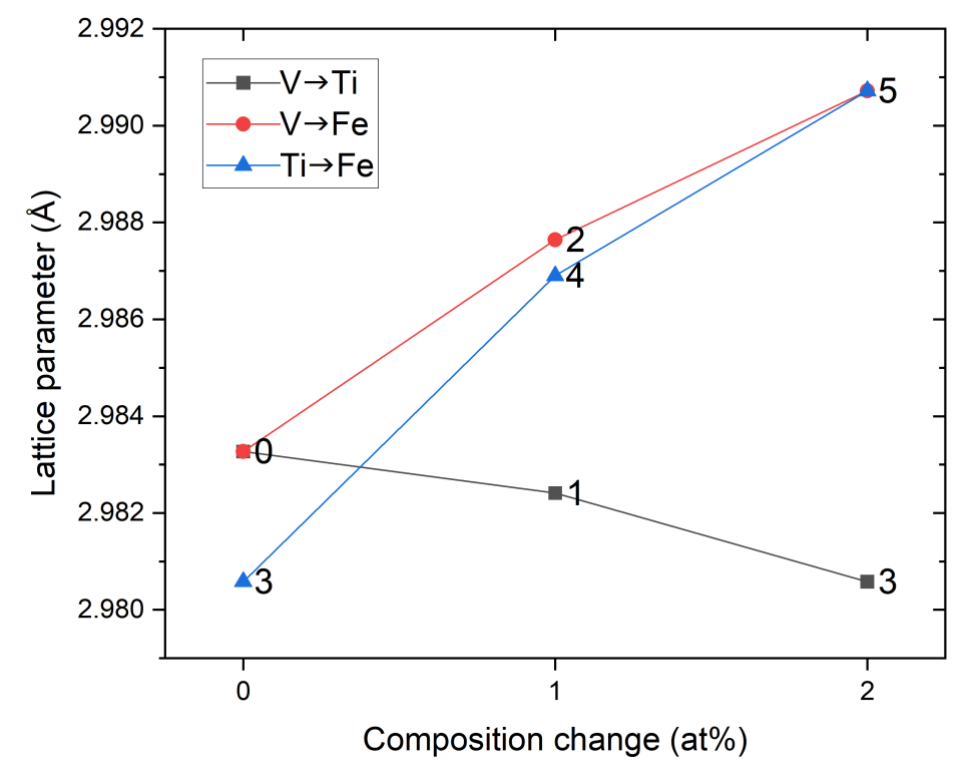

Figure 3. Lattice parameter change with composition for the series of the samples, $0 \rightarrow 1 \rightarrow 3,0 \rightarrow 2 \rightarrow 5$, and $3 \rightarrow 4 \rightarrow 5$. Sample IDs are annotated. In the legend, $\mathrm{V} \rightarrow \mathrm{Ti}$ denotes that $\mathrm{V}$ replaces Ti and likewise for the other cases.

BSE images of the samples in Figure 4 further validated the phase analysis from XRD. In Figure 4, only two contrasts were evident regardless of the sample ID. The EDX elemental map of sample 8 shown in Figure 5 revealed that the gray or dark contrast was the TiFe phase. The white or bright contrast showed enrichment of $\mathrm{Ce}$ and $\mathrm{O}$, and they corresponded to phases $\mathrm{Ce}$ and/or $\mathrm{CeO}_{2}$. The area fractions evaluated for gray and white contrast are summarized in Table 3 and in good agreement with the phase fractions from XRD data in Table 2. Thus, the above observation suggests that phases and their relative fractions obtained after melting and heat treatment were in confirmation with the respective intentionally designed alloys.

Table 3. Phase analysis of the samples from the SEM micrographs. The phase fractions from the BSE images.

\begin{tabular}{cccc}
\hline \multirow{2}{*}{ Sample ID } & Nominal Composition & \multicolumn{2}{c}{ Phase Fraction (Area\%) } \\
\cline { 3 - 4 } & & Gray & White \\
\hline 0 & $\mathrm{Ti}_{51} \mathrm{Fe}_{49}$ & 96.9 & 3.1 \\
1 & $\mathrm{Ti}_{50} \mathrm{Fe}_{49} \mathrm{~V}_{1}$ & 96.9 & 3.1 \\
2 & $\mathrm{Ti}_{51} \mathrm{Fe}_{48} \mathrm{~V}_{1}$ & 97.4 & 2.6 \\
3 & $\mathrm{Ti}_{49} \mathrm{Fe}_{49} \mathrm{~V}_{2}$ & 97.0 & 3.0 \\
4 & $\mathrm{Ti}_{50} \mathrm{Fe}_{48} \mathrm{~V}_{2}$ & 96.5 & 3.5 \\
5 & $\mathrm{Ti}_{51} \mathrm{Fe}_{47} \mathrm{~V}_{2}$ & 97.2 & 2.8 \\
6 & $\mathrm{Ti}_{46.5} \mathrm{Fe}_{48} \mathrm{~V}_{5.5}$ & 97.0 & 3.0 \\
7 & $\mathrm{Ti}_{46.5} \mathrm{Fe}_{47.5} \mathrm{~V}_{6}$ & 96.8 & 3.2 \\
8 & $\mathrm{Ti}_{46} \mathrm{Fe}_{47.5} \mathrm{~V}_{6.5}$ & 97.0 & 3.0 \\
\hline
\end{tabular}




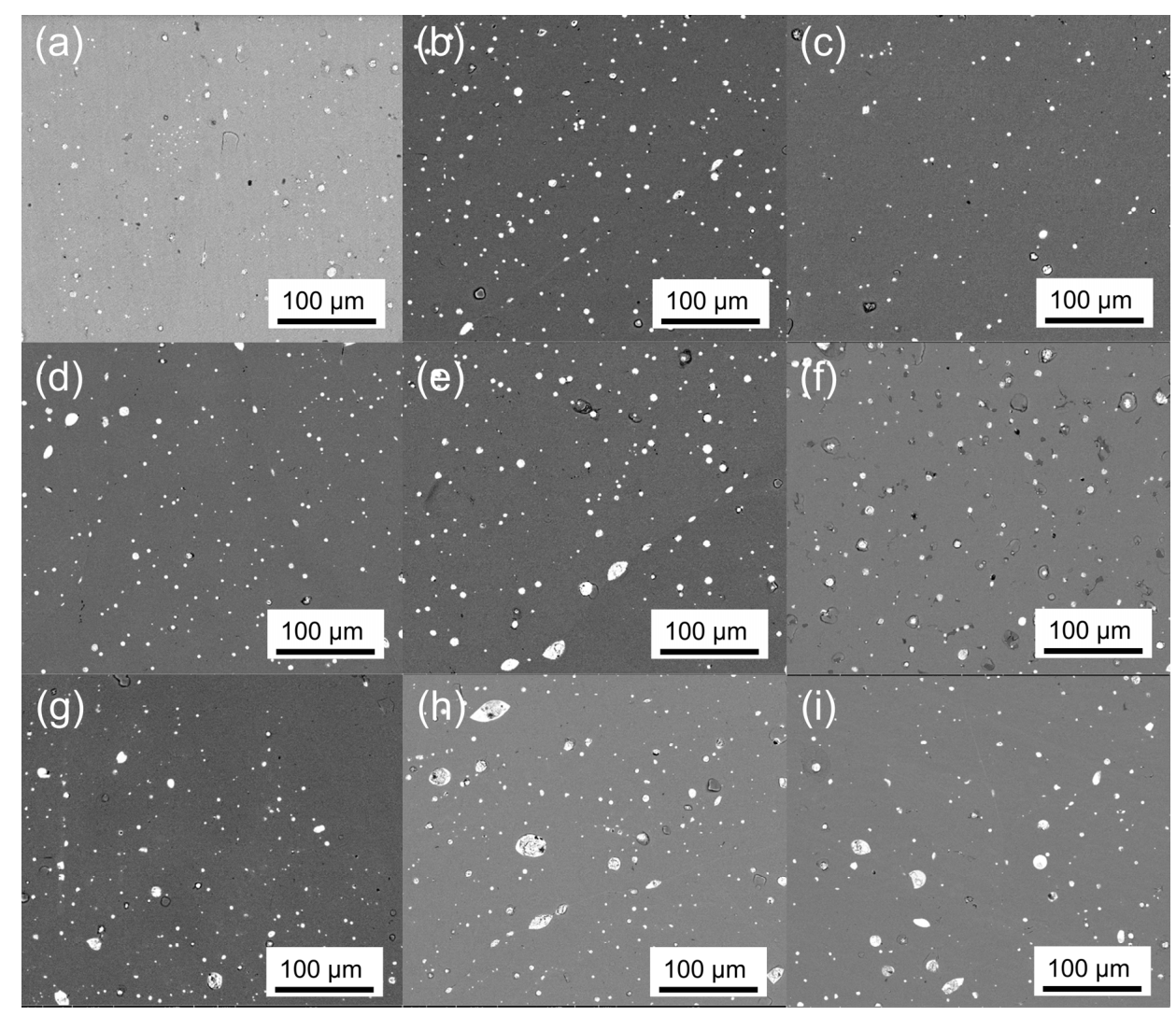

Figure 4. SEM BSE images of samples: (a) $0 ;$ (b) $1 ;$ (c) $2 ;$ (d) $3 ;$ (e) $4 ;$ (f) $5 ;$ (g) 6 ; (h) 7 ; (i) 8 .

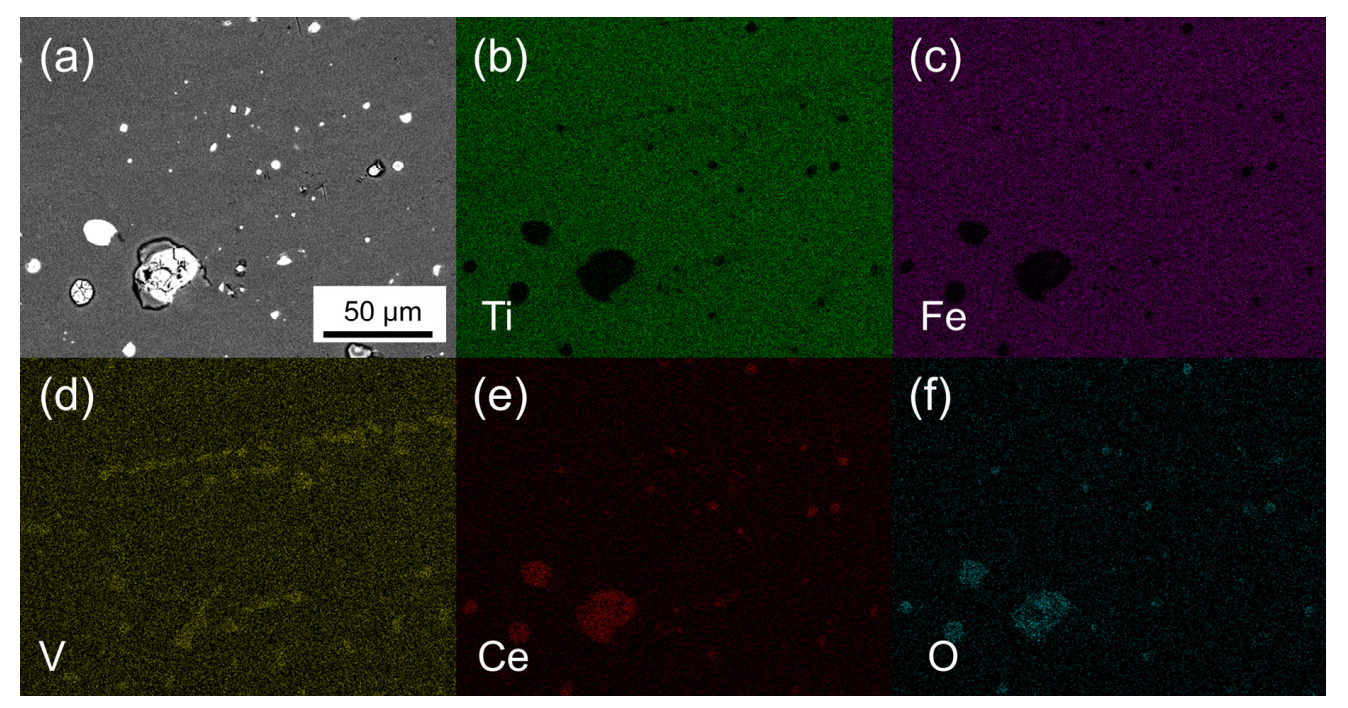

Figure 5. SEM BSE image and EDX elemental map of sample 8: (a) BSE image; (b) Ti; (c) Fe; (d) V; (e) $\mathrm{Ce}$; (f) $\mathrm{O}$.

\subsection{Activation and PCI Measurements}

Activation of alloys 0-8 was performed at $30^{\circ} \mathrm{C}$ under $3 \mathrm{MPa} \mathrm{H}_{2}$ pressure. As shown in Figure 6, all the alloys absorbed hydrogen under the above condition although the kinetics varied among the samples. The effect of Ce addition to TiFe-based alloys has been highlighted earlier [25], and also in our cases, the addition of $3 \mathrm{wt} \%$ Ce promoted activation. Complete activation of each alloy took three to five cycles of hydrogen absorption at $3 \mathrm{MPa}$ followed by evacuation under rough vacuum $\left(10^{-1} \mathrm{~Pa}\right)$ at $30^{\circ} \mathrm{C}$. 
In Figure 7, the PCI curves for the three series of the composition change are presented: $0 \rightarrow 1 \rightarrow 3,0 \rightarrow 2 \rightarrow 5$, and $3 \rightarrow 4 \rightarrow 5$, as the lattice parameter analysis in Figure 3. It can be seen that the desorption plateau pressures $P_{1}$ and $P_{2}$ for the starting composition 0 were positioned within $0.1-1 \mathrm{MPa}$, but pressure hysteresis in the absorption process limited the absorbed amount under $1 \mathrm{MPa}$, and further optimization of the composition was necessary. When comparing the plateau pressures, we focused on the desorption plateau pressures because the pressure hysteresis in Figure 7 was apparently affected by the composition and the absorption plateau pressures were less systematically changed by the composition change.

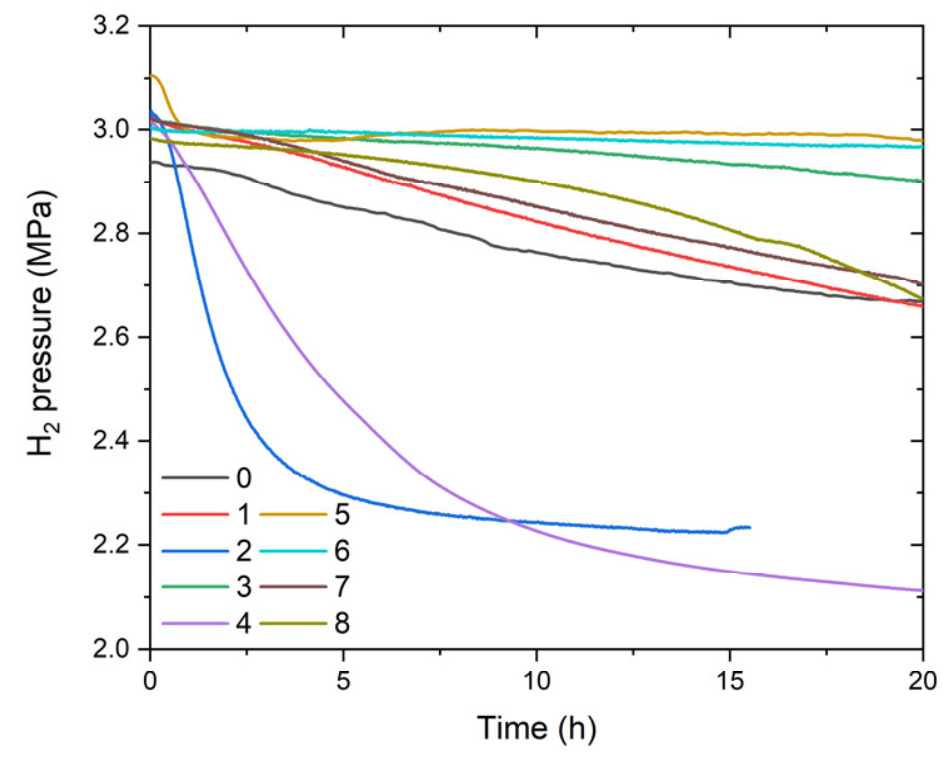

Figure 6. First-cycle activation profile for samples 0-8. The hydrogen pressure inside the closed reactor was recorded for $20 \mathrm{~h}$.
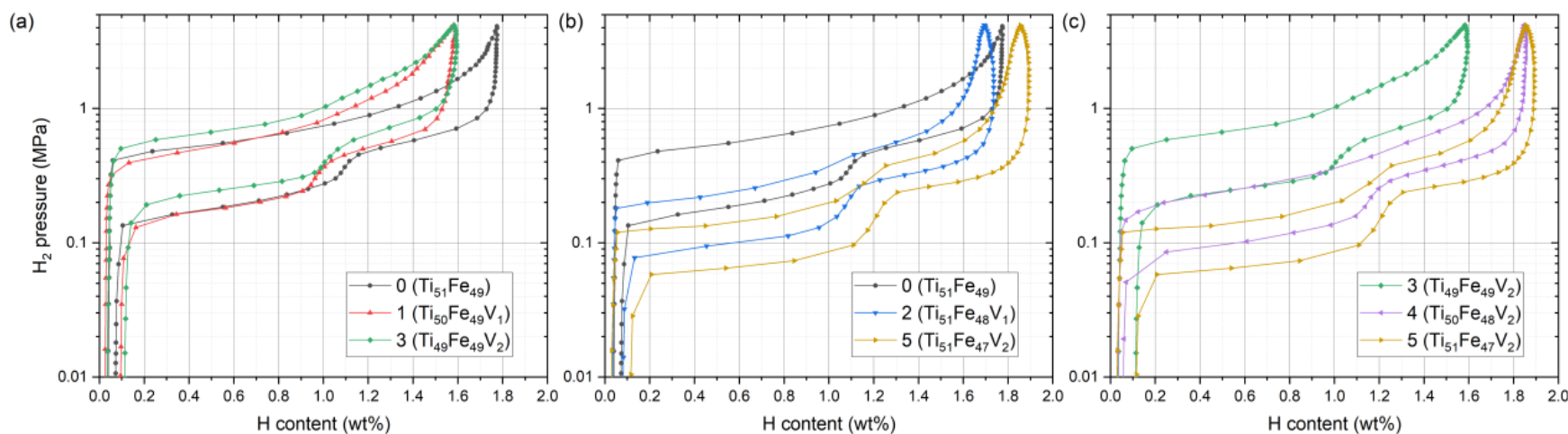

Figure 7. PCI curves for the three series of the samples measured at $30^{\circ} \mathrm{C}:(\mathbf{a}) 0,1$, and $3 ;$ (b) 0,2 , and $5 ;$ (c) 3,4 , and 5 .

We start the discussion with sample $0 \rightarrow 1 \rightarrow 3$ in Figure $7 \mathrm{a}$. As the composition of the alloy sample changed $0 \rightarrow 1$, there was no profound change in the plateau pressure. In contrast, with increasing $V$ from 1 to 2 at. $\%$, in $1 \rightarrow 3, P_{1}$ and $P_{2}$ certainly rose to higher pressures. Referring to the sublattice occupation in Table 1, Ti at Fe sublattice was replaced by $\mathrm{V}$ in $0 \rightarrow 1\left(\mathrm{Fe}_{49} \mathrm{Ti}_{1} \rightarrow \mathrm{Fe}_{49} \mathrm{~V}_{1}\right)$, whereas $\mathrm{Ti}$ at Ti sublattice was replaced by $\mathrm{V}$ in $1 \rightarrow 3$ $\left(\mathrm{Ti}_{50} \rightarrow \mathrm{Ti}_{49} \mathrm{~V}_{1}\right)$. Therefore, equilibrium pressure tailoring outcomes would differ depending on the V site occupancy [2]: Ti or V substitution at Fe sublattice changed the plateau pressure to a similar degree, but $\mathrm{V}$ substitution at Ti sublattice raised the plateau pressures. The PCI curves of the second series $0 \rightarrow 2 \rightarrow 5$, plotted in Figure $7 \mathrm{~b}$, displayed a monotonic decrease in the plateau pressures. Different from the aforementioned $0 \rightarrow 1 \rightarrow 3$ series, here 
only Fe at Fe sublattice was replaced by $\mathrm{V}$ as $\mathrm{V}$ concentration increased from 0 to 2 at.\%. In the last series, $3 \rightarrow 4 \rightarrow 5$ in Figure $7 \mathrm{c}, P_{1}$ and $P_{2}$ again decreased monotonically. However, the drop in $3 \rightarrow 4$ was more pronounced than that in $4 \rightarrow 5$. This is also related to the underlying substitution mechanism in Table 1. At the Fe sublattice, the occupation change in $3 \rightarrow 4\left(\mathrm{Fe}_{49} \mathrm{~V}_{1} \rightarrow \mathrm{Fe}_{48} \mathrm{~V}_{2}\right)$ and $4 \rightarrow 5\left(\mathrm{Fe}_{48} \mathrm{~V}_{2} \rightarrow \mathrm{Fe}_{47} \mathrm{Ti}_{1} \mathrm{~V}_{2}\right)$ was the increase of either $\mathrm{V}$ or $\mathrm{Ti}$ by 1 at. $\%$, and we found that the effect on the pressure change was similar. However, there was an additional change in the Ti sublattice occupation in $3 \rightarrow 4\left(\mathrm{Ti}_{49} \mathrm{~V}_{1} \rightarrow \mathrm{Ti}_{50}\right)$, and this resulted in a more significant drop in $P_{1}$ and $P_{2}$ in the case of $3 \rightarrow 4$. Therefore, the plateau pressure change is comprehensible only when the sublattice occupation is considered [40]: the nominal composition change does not provide full understanding. To clearly visualize the pressure variation, $P_{1}$ and $P_{2}$ were taken at the midpoint of the desorption plateaus and are plotted in Figure 8.
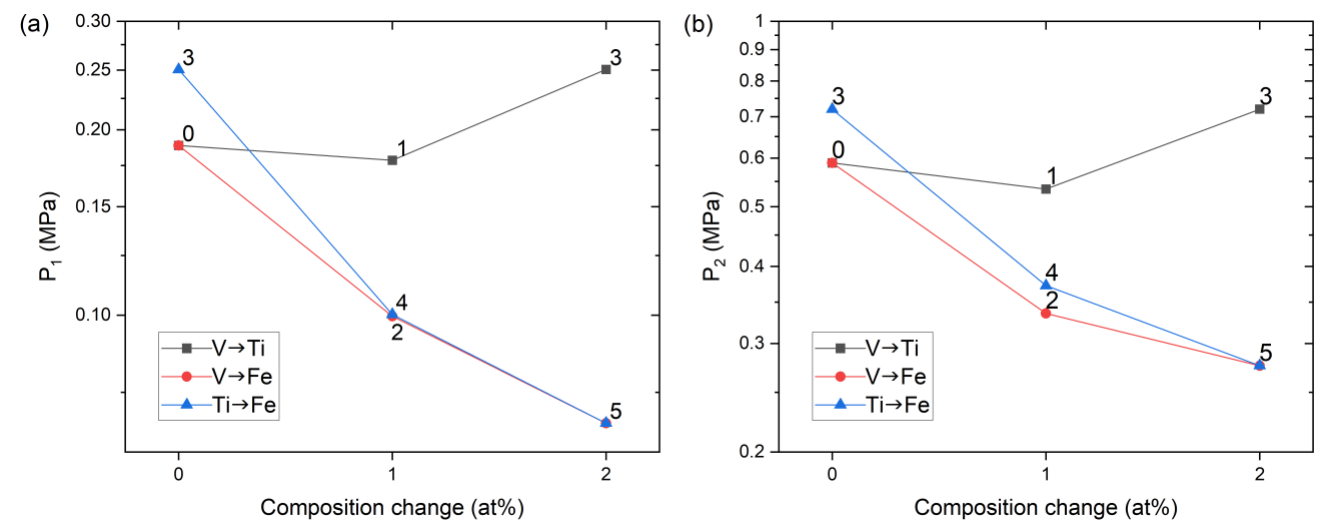

Figure 8. Variation of the desorption plateau pressures (a) $P_{1}$ and (b) $P_{2}$ for the three series of the samples in Figure 7. Sample IDs are annotated. In the legend, $\mathrm{V} \rightarrow \mathrm{Ti}$ denotes that $\mathrm{V}$ replaces Ti and likewise for the other cases.

Based on the PCI results, we established a strategy to maximize the usable capacity between 0.1 and $1 \mathrm{MPa}: P_{2}$ is lowered through $\mathrm{V}$ substitution at Fe sublattice, and then $P_{1}$ is raised by $\mathrm{V}$ substitution at Ti sublattice. In Figure $8, P_{2}$ of the samples 2,4 , and 5 is low enough to ensure a high amount of hydrogen absorption under 1 MPa even with pressure hysteresis. Therefore $2-3$ at. $\% \mathrm{~V}$ at Fe sublattice can bring down the $P_{2}$ value to the desired pressure range. However, then their $P_{1}$ values become too low to fully desorb hydrogen under $0.1 \mathrm{MPa}$. Considering the increase in $P_{1}$ in $1 \rightarrow 3$ when 1 at. $\%$ of $\mathrm{V}$ replaced Ti, 3-4 at.\% $\mathrm{V}$ at Ti sublattice would be needed to make $P_{1}$ similar to $P_{2}$. Under this logic, we designed three new compositions: $\mathrm{Ti}_{46.5} \mathrm{Fe}_{48} \mathrm{~V}_{5.5}$ (sample 6), $\mathrm{Ti}_{46.5} \mathrm{Fe}_{47.5} \mathrm{~V}_{6}$ (sample 7), and $\mathrm{Ti}_{46} \mathrm{Fe}_{47.5} \mathrm{~V}_{6.5}$ (sample 8). A precaution was taken when preparing these samples. In Figure 1, the black dashed line is the liquidus surface projection, overlaid on a portion of the isothermal section of the Ti-Fe-V phase diagram at $1000{ }^{\circ} \mathrm{C}$ [38]. The alloy composition marked as $\mathrm{B}\left(\mathrm{Ti}_{45} \mathrm{Fe}_{50} \mathrm{~V}_{5}\right)$ is located in the region where $\mathrm{C} 14$ is solidified first from liquid. This composition contained $10 \mathrm{wt}$.\% of the C14 phase even after 1 week of annealing in a previous study [2], and it would require a longer annealing time to reach thermodynamic equilibrium, i.e., a single B2 phase. It was shown in another study that the alloy composition marked as $\mathrm{M}\left(\mathrm{Ti}_{47} \mathrm{~V}_{5} \mathrm{Fe}_{48}\right)$, which is on the liquidus surface projection line that divides the region of B2 and C14, resulted in an almost-B2 phase after three weeks of annealing [37]. Therefore, samples 6-8 need a longer annealing time than that applied for samples 0-5 (one week), and they were annealed for three weeks at $1000{ }^{\circ} \mathrm{C}$. The XRD data in Figure $2 \mathrm{~g}-\mathrm{i}$ for samples $6-8$ confirmed that they only contained the TiFe phase in the $\mathrm{B} 2$ structure except for $\mathrm{Ce}$ and $\mathrm{CeO}_{2}$; we did not find the peaks of the $\mathrm{C} 14$ phase.

Figure 9a shows the PCI curves for samples 6, 7, and 8 measured at $30^{\circ} \mathrm{C}$. As intended, $P_{1}$ and $P_{2}$ were located closely for all of them, and the two-step desorption plateaus became almost a single plateau. Although it is a subtle difference, $P_{1}$ of sample 7 was the lowest 
because it contained more $\mathrm{V}$ at Fe sublattice than sample 6 and less $\mathrm{V}$ at Ti sublattice than sample 8; this again proves that the equilibrium pressure can be precisely engineered if the effect of substitution at each sublattice is well understood. All of them turned out to be suitable to be used between the target pressure range of 0.1-1 MPa. Among them, sample 8 displayed the best performance. Although further analyses are necessary, it is also possible that the smaller maximum hydrogen content in samples 6 and 7 could have originated from the failure of full activation of the samples rather than from the difference in composition. Samples 1 and 3 in Figure 7a also displayed smaller maximum capacities, and there is no apparent reason why such a small change in composition can significantly affect the maximum capacity. Their PCI curves look squeezed along the abscissa, and it indicates that some part of the samples remained unactivated. To determine the reproducibility of the PCI curve of sample 8, another measurement was performed and presented as \#2 in Figure 9b. The data were not from the consecutive cycle of \#1 but an independent measurement with a new sampling and the activation process.
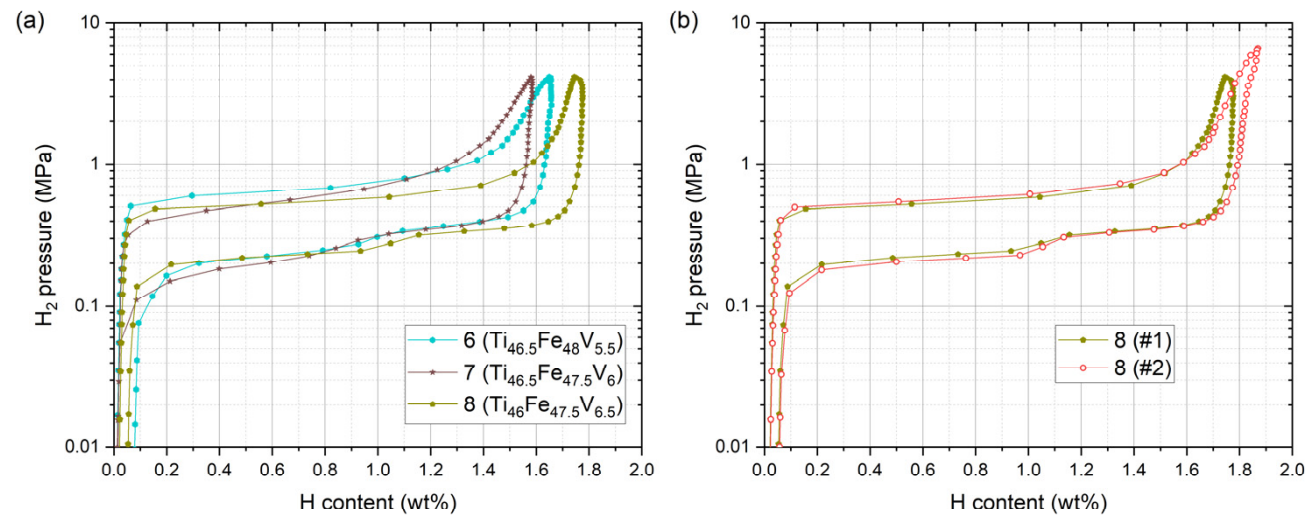

Figure 9. (a) PCI curves for samples 6,7 , and 8 at $30^{\circ} \mathrm{C}$. (b) Comparison of the two independently measured PCI curves for sample 8.

Continuing the discussion on the usable capacity, sample 8 , showing the best performance, absorbed $\sim 1.6 \mathrm{wt} . \% \mathrm{H}$ under $1 \mathrm{MPa}$ and desorbed most of the absorbed hydrogen at $0.1 \mathrm{MPa}$, resulting in $1.5 \mathrm{wt} . \%$ of usable hydrogen-storage capacity in this range. This surpasses the maximum capacity of $1.4 \mathrm{wt} . \%$ of $\mathrm{LaNi}_{5}\left(\mathrm{LaNi}_{5}\right.$ to $\left.\mathrm{LaNi}_{5} \mathrm{H}_{6}\right)$ and highlights the potential of TiFe-based alloy as a room-temperature hydrogen-storage material. Further improvement in the usable capacity by increasing $\mathrm{V}$ content is conceivable. However, as shown in Figure 1, composition 8 is close to the phase boundary of the B2 single phase, and the $\mathrm{V}$ content is limited by thermodynamics. Therefore we do not expect any significant improvement in the usable capacity by further increasing $\mathrm{V}$ content.

The enthalpy and entropy change of hydrogen desorption of sample 8 was characterized by measuring PCI curves at 40 and $50{ }^{\circ} \mathrm{C}$, and the results are shown in Figure 10a. The $P_{1}$ and $P_{2}$ from the desorption plateaus were taken at $\mathrm{H} / \mathrm{M}=0.25(0.486 \mathrm{wt} . \% \mathrm{H})$ and $\mathrm{H} / \mathrm{M}=0.7(1.361 \mathrm{wt} . \% \mathrm{H})$, respectively, where $\mathrm{H} / \mathrm{M}$ is the hydrogen to metal ratio, and van't Hoff plots are shown in Figure 10b. The enthalpy change $(\Delta H)$ and entropy change $(\Delta S)$ per one mole of hydrogen were obtained from the slope and the intercept of the linear regression result. The obtained values are: $\Delta H_{1}=25.1 \pm 0.4 \mathrm{~kJ} \mathrm{~mol}^{-1}$ and $\Delta H_{2}=34.4 \pm 2.2 \mathrm{~kJ} \mathrm{~mol}^{-1}$, and $\Delta S_{1}=89.3 \pm 1.2 \mathrm{~J} \mathrm{~K}^{-1} \mathrm{~mol}^{-1}$ and $\Delta S_{2}=123.8 \pm 7.0 \mathrm{~J} \mathrm{~K}^{-1} \mathrm{~mol}^{-1}$. Compared to the enthalpy change of pure TiFe, $\Delta H_{1}=28.1 \mathrm{~kJ} \mathrm{~mol}^{-1}$ and $\Delta H_{2}=33.3 \mathrm{~kJ} \mathrm{~mol}^{-1}$ (at $\mathrm{H} / \mathrm{M}=0.7$ ) by Reilly and Wiswall [1] and $\Delta H_{1}=25.6 \pm 1.0$ and $\Delta H_{2}=31.6 \pm 1.2 \mathrm{~kJ} \mathrm{~mol}^{-1}$ (at $\mathrm{H} / \mathrm{M}=0.7$ ) by Wenzl and Lebsanft [41], $\Delta H_{1}$ was down-shifted and $\Delta H_{2}$ was up-shifted. Especially, the difference, $\Delta H_{2}-\Delta H_{1}$, was appreciably larger in sample 8. Hence the decrease in $P_{2}$ (i.e., stabilization of dihydride and larger $\Delta H_{2}$ ) and the increase in $P_{1}$ (i.e., destabilization of monohydride and smaller $\Delta H_{1}$ ) by $\mathrm{V}$ substitution were correctly captured in the enthalpy change. 

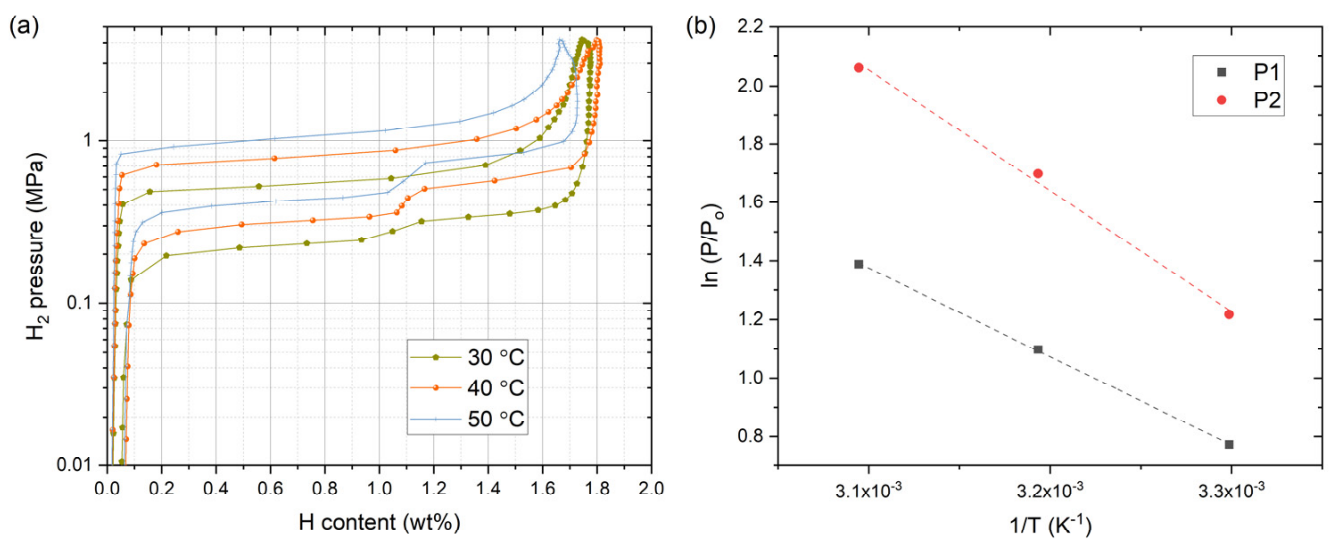

Figure 10. (a) PCI curves for sample 8 at 30, 40, and $50{ }^{\circ} \mathrm{C}$; (b) van't Hoff plots of the desorption plateau pressures for sample 8 . The dashed lines in $(\mathbf{b})$ are the linear regression results and $P_{0}=1.01325 \times 10^{5} \mathrm{~Pa}$.

\section{Conclusions}

The objectives of the present investigation were twofold: (1) design of a TiFe alloy with a maximum usable hydrogen-storage capacity in a target pressure range (0.1-1 MPa) and (2) easy RT activation of the TiFe alloy via Ce addition. Enhancement in the usable storage capacity was achieved via $\mathrm{V}$ substitution. The unique characteristic of $\mathrm{V}$, i.e., appreciable substitution at both $\mathrm{Ti}$ and Fe sublattices, was exploited to tailor the plateau pressures. The cue to enhance hydrogen-storage capacity is the reduction in the $P_{2} / P_{1}$ ratio: $P_{2}$ was lowered by $\mathrm{V}$ substitution at Fe sublattice whereas $P_{1}$ was raised by $\mathrm{V}$ substitution at Ti sublattice. The addition of $3 \mathrm{wt} . \%$ Ce promoted activation at room temperature and suppressed the formation of $\mathrm{Ti}_{4} \mathrm{Fe}_{2} \mathrm{O}_{1-x}$ suboxide, which enabled better control of the composition of the TiFe phase. Among the series of the Ti-Fe-V alloys, composition $\mathrm{Ti}_{46} \mathrm{Fe}_{47.5} \mathrm{~V}_{6.5}$ exhibited the maximum usable capacity of $1.5 \mathrm{wt} . \%$ under $1 \mathrm{MPa}$ of absorption and $0.1 \mathrm{MPa}$ of desorption pressure at $30^{\circ} \mathrm{C}$. The enthalpy change of hydrogen desorption was $\Delta H_{1}=25.1 \pm 0.4 \mathrm{~kJ} \mathrm{~mol}^{-1}$ and $\Delta H_{2}=34.4 \pm 2.2 \mathrm{~kJ} \mathrm{~mol}^{-1}$, providing an increased value of $\Delta H_{2}-\Delta H_{1}$ compared to pure TiFe.

Author Contributions: Conceptualization, M.F. and Y.-S.L.; Formal Analysis, M.F., J.-H.K. and Y.-S.L.; Investigation, M.F. and J.-H.K.; Writing-Original Draft Preparation, M.F. and J.-H.K.; Writing-Review and Editing, Y.W.C., J.-Y.S. and Y.-S.L.; Visualization, M.F., J.-H.K. and Y.-S.L.; Supervision, J.J. and J.-H.S.; Project Administration, Y.W.C. and J.-Y.S.; Funding Acquisition, Y.-S.L. All authors have read and agreed to the published version of the manuscript.

Funding: This research was funded by the Korea Institute of Science and Technology (grant number 2E30993) and by the "Technology Development Program to Solve Climate Changes" of the National Research Foundation funded by the Ministry of Science and ICT of Korea (NRF-2020M1A2A2080881).

Institutional Review Board Statement: Not applicable.

Informed Consent Statement: Not applicable.

Data Availability Statement: Not applicable.

Conflicts of Interest: The authors declare no conflict of interest.

\section{References}

1. Reilly, J.J.; Wiswall, R.H. Formation and properties of iron titanium hydride. Inorg. Chem. 1974, 13, 218-222. [CrossRef]

2. Jung, J.Y.; Lee, Y.S.; Suh, J.Y.; Huh, J.Y.; Cho, Y.W. Tailoring the equilibrium hydrogen pressure of TiFe via vanadium substitution. J. Alloys Compd. 2021, 854, 157263-157272. [CrossRef]

3. Lee, S.M.; Perng, T.P. Correlation of substitutional solid solution with hydrogenation properties of $\mathrm{TiFe}_{1-\mathrm{x}} \mathrm{M}_{\mathrm{x}}(\mathrm{M}=\mathrm{Ni}, \mathrm{Co}, \mathrm{Al})$ alloys. J. Alloys Compd. 1999, 291, 254-261. [CrossRef] 
4. Bououdina, M.; Fruchart, D.; Jacquet, S.; Pontonnier, L.; Soubeyroux, J.L. Effect of nickel alloying by using ball milling on the hydrogen absorption properties of TiFe. Int. J. Hydrogen Energy 1999, 24, 885-890. [CrossRef]

5. Lee, S.M.; Perng, T.P. Effect of the second phase on the initiation of hydrogenation of $\mathrm{TiFe}_{1-\mathrm{x}} \mathrm{M}_{\mathrm{x}}(\mathrm{M}=\mathrm{Cr}, \mathrm{Mn})$ alloys. Int. J. Hydrogen Energy 1994, 19, 259-263. [CrossRef]

6. Oguro, K.; Osumi, Y.; Suzuki, H.; Kato, A.; Imamura, Y.; Tanaka, H. Hydrogen storage properties of $\mathrm{TiFe}_{1-\mathrm{x}} \mathrm{Ni}_{\mathrm{y}} \mathrm{M}_{\mathrm{z}}$ alloys. J. Less-Common. Met. 1983, 89, 275-279. [CrossRef]

7. Qu, H.; Du, J.; Pu, C.; Niu, Y.; Huang, T.; Li, Z.; Lou, Y.; Wu, Z. Effects of Co introduction on hydrogen storage properties of Ti-Fe-Mn alloys. Int. J. Hydrogen Energy 2015, 40, 2729-2735. [CrossRef]

8. Patel, A.K.; Duguay, A.; Tougas, B.; Neumann, B.; Schade, C.; Sharma, P.; Huot, J. Study of the Microstructural and First Hydrogenation Properties of TiFe Alloy with Zr, Mn and V as Additives. Processes 2021, 9, 1217-1228. [CrossRef]

9. Dematteis, E.M.; Dreistadt, D.M.; Capurso, G.; Jepsen, J.; Cuevas, F.; Latroche, M. Fundamental hydrogen storage properties of TiFe-alloy with partial substitution of Fe by Ti and Mn. J. Alloys Compd. 2021, 874, 159925-159936. [CrossRef]

10. Dematteis, E.M.; Berti, N.; Cuevas, F.; Latroche, M.; Baricco, M. Substitutional effects in TiFe for hydrogen storage: A comprehensive review. Mater. Adv. 2021, 2, 2524-2560. [CrossRef]

11. Zeng, L.; Xu, G.; Liu, L.; Bai, W.; Zhang, L. Experimental investigation of phase equilibria in the Ti-Fe-Zr system. Calphad 2018, 61, 20-32. [CrossRef]

12. Gosselin, C.; Santos, D.; Huot, J. First hydrogenation enhancement in TiFe alloys for hydrogen storage. J. Phys. D Appl. Phys 2017, 50, 375303-375308. [CrossRef]

13. Lv, P.; Huot, J. Hydrogen storage properties of $\mathrm{Ti}_{0.95} \mathrm{FeZr}_{0.05}, \mathrm{TiFe}_{0.95} \mathrm{Zr}_{0.05}$ and $\mathrm{TiFeZr}_{0.05}$ alloys. Int. J. Hydrogen Energy 2016, 41, 22128-22133. [CrossRef]

14. Gosselin, C.; Huot, J. Hydrogenation Properties of TiFe Doped with Zirconium. Materials 2015, 8, 7864-7872. [CrossRef]

15. Jain, P.; Gosselin, C.; Huot, J. Effect of $\mathrm{Zr}, \mathrm{Ni}$ and $\mathrm{Zr}_{7} \mathrm{Ni}_{10}$ alloy on hydrogen storage characteristics of TiFe alloy. Int. J. Hydrogen Energy 2015, 40, 16921-16927. [CrossRef]

16. Lv, P.; Huot, J. Hydrogenation improvement of TiFe by adding ZrMn . Energy 2017, 138, 375-382. [CrossRef]

17. Faisal, M.; Suh, J.Y.; Lee, Y.S. Understanding first cycle hydrogenation properties of Ti-Fe-Zr ternary alloys. Int. J. Hydrogen Energy 2021, 46, 4241-4251. [CrossRef]

18. Kim, H.; Faisal, M.; Lee, S.I.; Jung, J.Y.; Kim, H.J.; Hong, J.; Lee, Y.S.; Shim, J.H.; Cho, Y.W.; Kim, D.H.; et al. Activation of Ti-Fe-Cr alloys containing identical $\mathrm{AB}_{2}$ fractions. Alloy. Compd. 2021, 864, 158876-158883. [CrossRef]

19. Jung, J.Y.; Lee, S.I.; Faisal, M.; Kim, H.; Lee, Y.S.; Suh, J.Y.; Shim, J.H.; Huh, J.Y.; Cho, Y.W. Effect of Cr addition on room temperature hydrogenation of TiFe alloys. Int. J. Hydrogen Energy 2021, 46, 19478-19485. [CrossRef]

20. Park, K.B.; Ko, W.S.; Fadonougbo, J.O.; Na, T.W.; Im, H.T.; Park, J.Y.; Kang, J.W.; Kang, H.S.; Park, C.S.; Park, H.K. Effect of Fe substitution by $\mathrm{Mn}$ and $\mathrm{Cr}$ on first hydrogenation kinetics of air-exposed TiFe-based hydrogen storage alloy. Mater. Charact. 2021, 178, 111246-111251. [CrossRef]

21. Bronca, V.; Bergman, P.; Ghaemmaghami, V.; Khatamian, D.; Manchester, F.D. Hydrogen absorption characteristics of an FeTi + misch metal alloy. J Less-Common Met. 1985, 108, 313-325. [CrossRef]

22. Wang, X.; Chen, R.; Chen, C.; Wang, Q. Hydrogen storage properties of $\mathrm{Ti}_{\mathrm{x}} \mathrm{Fe}+\mathrm{y}$ wt.\% La and its use in metal hydride hydrogen compressor. J. Alloys Compd. 2006, 425, 291-295. [CrossRef]

23. Singh, B.K.; Singh, A.K.; Srivastava, O.N. Improved hydrogen sorption characteristics in FeTi $1_{+} \mathrm{xMm}_{\mathrm{M}}$ material. Int. J. Hydrogen Energy 1996, 21, 111-117. [CrossRef]

24. Ma, J.; Pan, H.; Wang, X.; Chen, C.; Wang, Q. Hydrogen storage properties of $\mathrm{FeTi}_{1.3}+\mathrm{x}$ wt $\% \mathrm{Mm}(\mathrm{x}=0.0,1.5,3.0,4.5,6.0)$ hydrogen storage alloys. Int. J. Hydrogen Energy 2000, 25, 779-782. [CrossRef]

25. Leng, H.; Yu, Z.; Yin, J.; Li, Q.; Wu, Z.; Chou, K.-C. Effects of Ce on the hydrogen storage properties of $\mathrm{TiFe}_{0.9} \mathrm{Mn}_{0.1} \mathrm{alloy}$ Int. J. Hydrogen Energy 2017, 42, 23731-23736. [CrossRef]

26. Nagai, H.; Kitagaki, K.; Shoji, K. Microstructure and hydriding characteristics of FeTi alloys containing manganese. J. Less-Common Met. 1987, 134, 275-286. [CrossRef]

27. Liu, X.P.; Cuevas, F.; Jiang, L.J.; Latroche, M.; Li, Z.N.; Wang, S.M. Improvement of the hydrogen storage properties of Ti-Cr-V-Fe BCC alloy by Ce addition. J. Alloys Compd. 2009, 476, 403-407. [CrossRef]

28. Yan, Y.; Chen, Y.; Liang, H.; Zhou, X.; Wu, C.; Tao, M. Effect of Ce on the structure and hydrogen storage properties of $\mathrm{V}_{55} \mathrm{Ti}_{22.5} \mathrm{Cr}_{16.1} \mathrm{Fe}_{6.4}$. J. Alloys Compd. 2007, 429, 301-305. [CrossRef]

29. Bruzzone, G.; Costa, G.; Ferretti, M.; Olcese, G.L. Hydrogen storage in a beryllium substituted TiFe compound. Int. J. Hydrogen Energy 1980, 5, 317-322. [CrossRef]

30. Yang, T.; Wang, P.; Xia, C.; Liu, N.; Liang, C.; Yin, F.; Li, Q. Effect of chromium, manganese and yttrium on microstructure and hydrogen storage properties of TiFe-based alloy. Int. J. Hydrogen Energy 2020, 45, 12071-12081. [CrossRef]

31. Zadorozhnyy, V.Y.; Klyamkin, S.N.; Zadorozhnyy, M.Y.; Bermesheva, O.V.; Kaloshkin, S.D. Mechanical alloying of nanocrystalline intermetallic compound TiFe doped by aluminum and chromium. J. Alloys Compd. 2014, 586, S56-S60. [CrossRef]

32. Berdonosova, E.A.; Zadorozhnyy, V.Y.; Zadorozhnyy, M.Y.; Geodakian, K.V.; Zheleznyi, M.V.; Tsarkov, A.A.; Kaloshkin, S.D.; Klyamkin, S.N. Hydrogen storage properties of TiFe-based ternary mechanical alloys with cobalt and niobium. A thermochemical approach. Int. J. Hydrogen Energy 2019, 44, 29159-29165. [CrossRef] 
33. Johnson, J.R.; Reilly, J.J. The Use of Manganese Substituted Ferrotitanium Alloys for Energy Storage. In Proceedings of the International Conference on Alternative Energy Sources, Miami Beach, FL, USA, 5-7 December 1977.

34. Mintz, M.H.; Vaknin, S.; Biderman, S.; Hadari, Z. Hydrides of ternary TiFe $\mathrm{M}_{1-\mathrm{x}}(\mathrm{M}=\mathrm{Cr}, \mathrm{Mn}, \mathrm{Co}$, Ni) intermetallics. J. Appl. Phys 1981, 52, 463-467. [CrossRef]

35. Liu, J.; Lundin, C.E. Alloys for Hydrogen Storage. U.S. Patent 4358316, 1982.

36. Mitrokhin, S.V.; Verbetsky, V.N.; Kajumov, R.R.; Cunmao, H.; Yufen, Z. Hydrogen sorption peculiarities in FeTi-type Ti-Fe-V-Mn alloys. J. Alloys Compd. 1993, 199, 155-160. [CrossRef]

37. Massicot, B. Étude du Système Fe-Ti-V et de ses Applications au Stockage de L'hydrogène. Ph.D. Thesis, Université Paris-Est, Thiais, France, 2009.

38. Massicot, B.; Joubert, J.M.; Latroche, M. Phase equilibria in the Fe-Ti-V system. Int. J. Mat. Res. 2010, 101, 1414-1423. [CrossRef]

39. TOPAS Version 5; Bruker AXS GmbH: Karlsruhe, Germany, 2014.

40. Ko, W.S.; Park, K.B.; Park, H.K. Density functional theory study on the role of ternary alloying elements in TiFe-based hydrogen storage alloys. J. Mater. Sci. Technol. 2021, 92, 148-158. [CrossRef]

41. Wenzl, H.; Lebsanft, E. Phase diagram and thermodynamic parameters of the quasibinary interstitial alloy $\mathrm{Fe}_{0.5} \mathrm{Ti}_{0.5} \mathrm{H}_{\mathrm{x}}$ in equilibrium with hydrogen gas. J. Phys. F Met. Phys 1980, 10, 2147-2156. [CrossRef] 